\title{
Consensus Recommendations of the Multiple Sclerosis Study Group and Portuguese Neuroradiological Society for the Use of the Magnetic Resonance Imaging in Multiple Sclerosis in Clinical Practice: Part 1
}

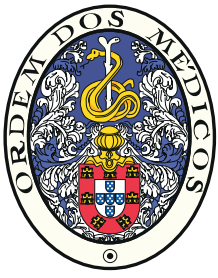

\author{
Recomendações e Consensos do Grupo de Estudos \\ de Esclerose Múltipla e da Sociedade Portuguesa de \\ Neurorradiologia sobre Ressonância Magnética na \\ Esclerose Múltipla na Prática Clínica: Parte 1
}

\author{
Pedro ABREU $\triangle^{1,2}$, Rui PEDROSA ${ }^{3}$, Maria José SÁ ${ }^{1,4}$, João CERQUEIRA ${ }^{5,6}$, Lívia SOUSA ${ }^{7,8}$, \\ Ana Martins DA SILVA ${ }^{9,10}$, Joaquim PINHEIRO ${ }^{11}$, João DE SÁ ${ }^{12,13}$, Sónia BATISTA ${ }^{7,8}$, Rita Moiron SIMÕES ${ }^{14}$, \\ Daniela Jardim PEREIRA ${ }^{15, *}$, Pedro VILELA ${ }^{16,17, *}$, José VALE ${ }^{14}$ \\ Acta Med Port 2018 May;31(5):281-289 - https://doi.org/10.20344/amp.10503
}

\section{ABSTRACT}

Introduction: Magnetic resonance imaging is established as a recognizable tool in the diagnosis and monitoring of multiple sclerosis patients. In the present, among multiple sclerosis centers, there are different magnetic resonance imaging sequences and protocols used to study multiple sclerosis that may hamper the optimal use of magnetic resonance imaging in multiple sclerosis. In this context, the Group of Studies of Multiple Sclerosis and the Portuguese Society of Neuroradiology, after a joint discussion, appointed a committee of experts to create recommendations adapted to the national reality on the use of magnetic resonance imaging in multiple sclerosis. The purpose of this document is to publish the first Portuguese consensus recommendations on the use of magnetic resonance imaging in multiple sclerosis in clinical practice.

Material and Methods: The Group of Studies of Multiple Sclerosis and the Portuguese Society of Neuroradiology, after discussion of the topic in national meetings and after a working group meeting held in Figueira da Foz on May 2017, have appointed a committee of experts that have developed by consensus several standard protocols on the use of magnetic resonance imaging in the diagnosis and follow-up of multiple sclerosis. The document obtained was based on the best scientific evidence and expert opinion. Subsequently, the majority of Portuguese multiple sclerosis consultants and departments of neuroradiology scrutinized and reviewed the consensus paper; comments and suggestions were considered. Technical magnetic resonance imaging protocols regarding diagnostic, monitoring and the recommended information to be included in the magnetic resonance imaging report will be published in a separate paper.

Results: We provide some practical guidelines to promote standardized strategies to be applied in the clinical practice setting of Portuguese healthcare professionals regarding the use of magnetic resonance imaging in multiple sclerosis.

Conclusion: We hope that these first Portuguese magnetic resonance imaging guidelines, based in the best available clinical evidence and practices, will serve to optimize multiple sclerosis management and improve multiple sclerosis patient care across Portugal.

Keywords: Demyelinating Diseases; Magnetic Resonance Imaging; Multiple Sclerosis; Practice Guidelines as Topic

RESUMO

Introdução: A esclerose múltipla caracteriza-se pela presença de lesões inflamatórias a nível do encéfalo e medula espinhal. A ressonância magnética é atualmente um exame indispensável no diagnóstico, na avaliação da atividade da doença e na resposta ao tratamento. Embora na nossa prática as vantagens da ressonância magnética estejam bem estabelecidas, continuam a existir

\footnotetext{
1. Serviço de Neurologia. Centro Hospitalar de São João. Porto. Portugal.

2. Departamento de Neurociências Clínicas e Saúde Mental. Faculdade de Medicina. Universidade do Porto. Porto. Portugal.

3. Serviço de Neurologia. Hospital dos Capuchos. Centro Hospitalar Lisboa Central. Lisboa. Portugal.

4. Unidade de Investigação, Energia, Ambiente e Saúde. Faculdade de Ciências da Saúde. Universidade Fernando Pessoa. Porto. Portugal.

5. Serviço de Neurologia. Hospital de Braga. Braga. Portugal.

6. Departamento de Neurologia. Escola de Medicina. Universidade do Minho. Braga. Portugal.

7. Serviço de Neurologia. Centro Hospitalar e Universitário de Coimbra. Coimbra. Portugal.

8. Faculdade de Medicina. Universidade de Coimbra. Coimbra. Portugal.

9. Serviço de Neurologia. Centro Hospitalar do Porto. Porto. Portugal.

10. Unidade de Investigação Multidisciplinar em Biomedicina. Departamento de Neurociências. Instituto de Ciências Biomédicas Abel Salazar. Universidade do Porto. Porto. Portugal.

11. Serviço de Neurologia. Hospital de Vila Nova de Gaia. Centro Hospitalar Vila Nova de Gaia/Espinho. Vila Nova de Gaia. Portugal.

12. Serviço de Neurologia. Hospital de Santa Maria. Centro Hospitalar de Lisboa Norte. Lisboa. Portugal.

13. Departamento de Neurociências. Faculdade de Medicina. Universidade de Lisboa. Lisboa. Portugal.

14. Serviço de Neurologia. Hospital Beatriz Ângelo. Loures. Portugal.

15. Serviço de Neurradiologia. Centro Hospitalar e Universitário de Coimbra. Coimbra. Portugal.

16. Serviço de Neurradiologia. Hospital Beatriz Ângelo. Loures. Portugal.

17. Serviço de Neurradiologia. Hospital da Luz. Lisboa. Portugal.

* Em representação da Sociedade Portuguesa de Neurorradiologia (SPNR) - Forum de Estudo da Esclerose Múltipla. Portugal.

$\triangle$ Autor correspondente: Pedro Abreu. pmabreu@netcabo.pt

Recebido: 08 de março de 2018 - Aceite: 02 de maio de 2018 | Copyright @ Ordem dos Médicos 2018
} 
dificuldades técnicas (uso de sequências e protocolos não padronizados) e clínicas (frequência de exames não adequada) que podem dificultar o diagnóstico e o seguimento dos doentes. Neste contexto, o Grupo de Estudos de Esclerose Múltipla e a Sociedade Portuguesa de Neurorradiologia, após discussão conjunta, designaram um comité de peritos para a criação de recomendações adaptadas à realidade nacional sobre a utilização da ressonância magnética na esclerose múltipla. O objetivo deste documento é publicar as primeiras recomendações de consenso portuguesas sobre a utilização da ressonância magnética na esclerose múltipla na prática clínica.

Material e Métodos: O Grupo de Estudos de Esclerose Múltipla e a Sociedade Portuguesa de Neurorradiologia, após discussão do tema em reuniões de âmbito nacional e de uma reunião do grupo de trabalho que teve lugar na Figueira da Foz em maio de 2017, designaram um comité de peritos que elaboraram por método de consenso vários protocolos padronizados sobre o uso da ressonância magnética no diagnóstico e seguimento da esclerose múltipla. $\mathrm{O}$ documento teve como base a melhor evidência científica e a opinião dos peritos. Posteriormente, o documento foi enviado para escrutínio à maioria dos responsáveis de consulta de esclerose múltipla e dos departamentos de neurorradiologia; os comentários e sugestões foram considerados. Os protocolos técnicos referentes à aquisição de imagem e a informação que deverá constar no relatório destes exames serão publicados numa publicação separada. Resultados: Neste artigo são propostas várias orientações práticas para promover estratégias padronizadas para serem aplicadas na prática clínica dos profissionais de saúde portugueses no que se refere ao uso da ressonância magnética na esclerose múltipla.

Conclusão: Os autores esperam que estas primeiras orientações portuguesas, sobre a utilização da ressonância magnética na esclerose múltipla na prática clínica, baseadas nas melhores evidências e práticas clínicas disponíveis, sirvam para otimizar a gestão da esclerose múltipla e melhorar o tratamento destes doentes em Portugal.

Palavras-chave: Doenças Desmielinizantes; Esclerose Múltipla; Protocolos; Ressonância Magnética

\section{INTRODUCTION}

Multiple sclerosis (MS) is a chronic autoimmune demyelinating inflammatory and degenerative disease of the central nervous system (CNS) that affects people usually between 17 and 65 years old and is twice as common in women than men. ${ }^{1} \mathrm{MS}$ may cause permanent disability and affects patients' quality of life negatively. ${ }^{1}$ Portugal is a medium risk country for MS with an estimated incidence in 1998 - 2007 of 4.48 per 100000 habitants in northern Lisbon, Portugal. ${ }^{2}$

Due to its high sensibility and specificity in detecting demyelinating lesions and differential diagnosis capability, since 2001, brain and spinal cord magnetic resonance imaging (MRI) is included in MS diagnostic criteria. ${ }^{3-5} \mathrm{MRI}$ diagnostic value was recently stressed in the revision of the MAGNIMS MS diagnostic criteria. ${ }^{6}$ However, MRI importance in MS is not confined to its diagnosis, since it has a well-known role in the understanding of its pathophysiology, in phenotype descriptions, in prognosis, in monitoring of individual therapeutic responses, in monitoring potential MS treatments adverse effects and, finally, as a surrogate marker in clinical trials. ${ }^{7-10}$

At present, in Portugal as in other countries, there are different MRI sequences and protocols used to study MS; moreover, the frequency and the clinical situations in which this test is performed in MS also vary among MS centers. , $11,12^{11}$ This may hamper and negatively influence the optimal use of MRI in MS.9,11-13 To overcome this problem standardized protocols and guidelines on the optimal use of MRI were published..$^{8,9,12-19}$ In Portugal, after several meetings and clinical discussions, neurologists and neuroradiologists dedicated to MS patients' treatment have decided that there was a need to create a standardized protocol and guidelines, adapted to our national reality, on the use of MRI in MS, as recognized by other experts in the field. ${ }^{8,20}$

The goal of this document is to publish a Portuguese consensus recommendations agreement regarding the use of MRI in MS, on the clinical practice setting, based on the professional experience and the best scientific evidence.
It is our hope that these recommendations and guidance may be implemented in everyday clinical practice, in our nationwide MS centers and Neuroradiology departments.

\section{MATERIAL AND METHODS}

In 2017 the Grupo de Estudos de Esclerose Múltipla (GEEM, the main Portuguese healthcare professionals group dedicated to MS study and treatment, supported by the Portuguese Neurological Society) and the Portuguese Society of Neuroradiology (SPNR) nominated, from among their respective members, a group of experts, originating from academic and community-based MS centers, to convey and write the first draft of a consensus, based on the best available scientific evidence and clinical expertise. After several rounds of internal discussions, the expert-group consensus recommendations agreement and standardized protocols on the use of MRI in the diagnosis and monitoring of MS, were circulated by among the members of the two scientific societies, for suggestions and feedback which were then synthesized and incorporated in the final version of the manuscript. Technical MRI protocols regarding diagnostic, monitoring and the recommended information to be included in the MRI report will be published in a separate paper.

\section{RESULTS}

\section{MRI and MS diagnosis}

The diagnosis of MS is based on clinical evaluation and in the demonstration of demyelinating lesions dissemination in space (DIS) and time (DIT) and exclusion of alternative disorders that can mimic this condition. ${ }^{4}$

MRI has high sensibility to detect MS lesions, is widely available, reproducible, and provides objective measures of disease activity and burden, so and without surprise it became, since 2001, with the publication of the now extensively accepted MS McDonald criteria, a mainstay of MS diagnosis. ${ }^{3,16}$ These criteria incorporated, for the first time, brain and spinal lesions in the MS diagnostic algorithm and introduced the definition of MRI DIS and DIT., ${ }^{3,8}$ In 2005 
and 2010 the McDonald criteria suffered revisions that simplified the demonstration of lesion DIT, better defined the role of spinal cord lesions in demonstrating DIS and simplified primary-progressive MS diagnosis (Table 1).,4,5,21

It is now well accepted that the McDonald criteria allowed clinicians to accurately make a MS diagnosis sooner, which permitted an earlier start of a disease-modifying treatment (DMT) and had a favorable impact in MS prognosis. , $16^{16}$

Nevertheless, the last revised McDonald criteria have been criticized for their complexity, their somewhat low diagnostic specificity, that may lead to overdiagnosis, the absence of other paraclinical tests in the diagnostic algorithm, such as cerebrospinal fluid (CSF) study, which may be useful in the differential diagnosis of patients that don't fulfill MRI criteria or have unusual or uncertain MS presentations, and finally for limitations in the diagnosis of primary progressive MS (PPMS). ${ }^{12}$
To rule out these issues the European collaborative research group that studies MRI in MS (MAGNIMS) proposed a new MRI MS diagnosis criteria consensus guideline (Table 2) in 2016 and latter on the McDonald criteria (Table 3) were updated in 2017.6,22 Nevertheless and in spite of the overall expectations, the $2017 \mathrm{McD}$ onald criteria did not take into account all the proposed DIS MAGNINS MRI MS criteria (particularly they didn't accept three or more periventricular lesions and one or more optic nerve lesion as DIS criteria), they advanced a MS diagnosis in a typical clinical isolated syndrome (CIS) if DIS and cerebrospinal fluid (CSF)-specific oligoclonal bands (OCBs) are present and maintained the PPMS criteria (Table 3). ${ }^{6,22}$

In the 2017 McDonald criteria, on a CIS case, if there is a typical clinical presentation of MS and no other disease that would better explain the patient clinical features is suspected, a diagnosis of possible MS may be done. ${ }^{22}$

Table 1 - MS diagnosis criteria (adapted from ref. 4)

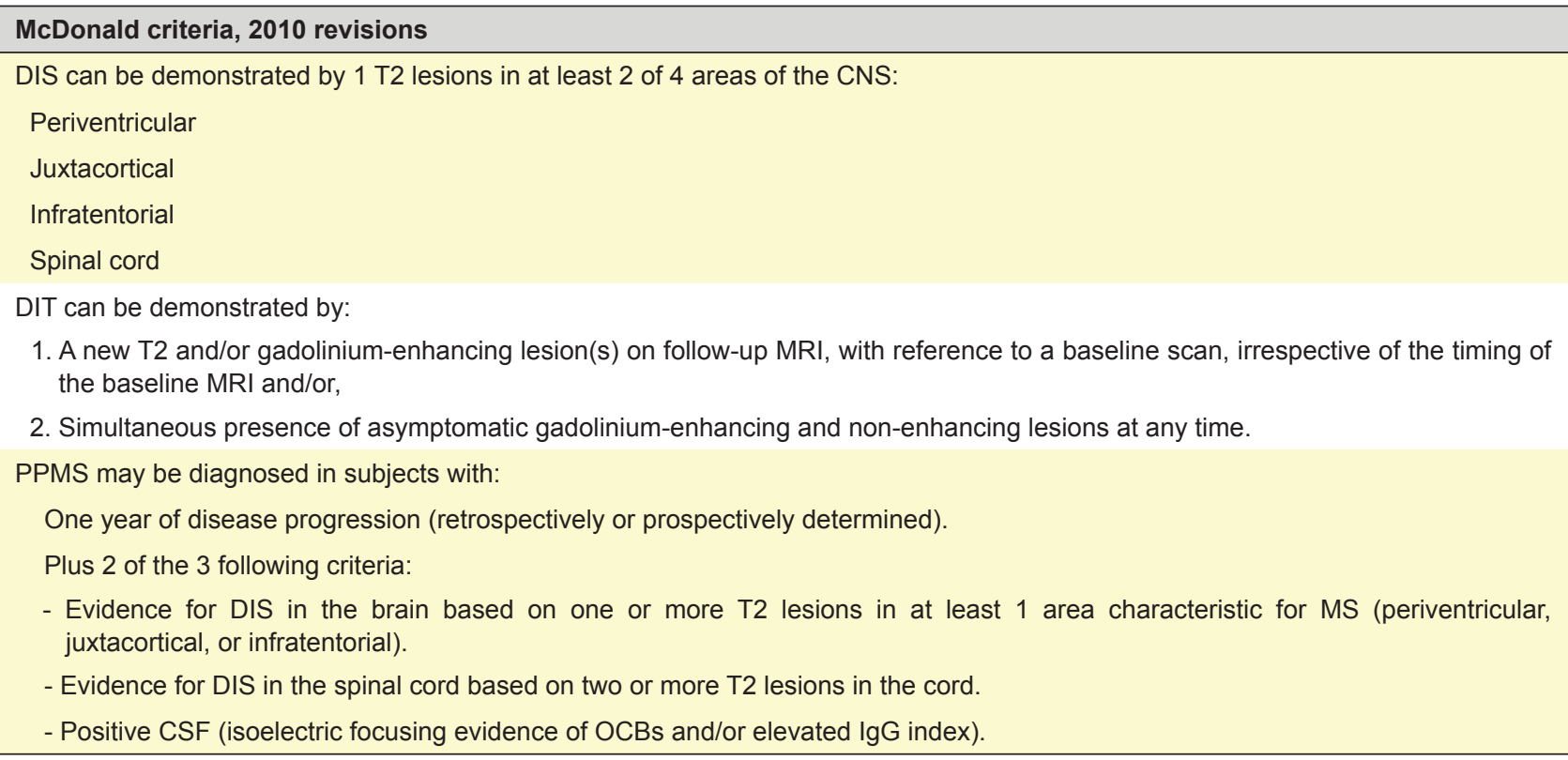

Table 2 - MS diagnosis criteria (adapted from ref. 6)

\section{MAGNIMS MRI Criteria, 2016}

Dissemination in space can be shown by involvement of at least two of five areas of the CNS as follows:

Three or more periventricular lesions

One or more infratentorial lesion

One or more spinal cord lesion

One or more optic nerve lesion

One or more cortical or juxtacortical lesion

Dissemination in time can be demonstrated by:

1. A new T2 and/or gadolinium-enhancing lesion(s) on follow-up MRI, with reference to a baseline scan, irrespective of the timing of the baseline MRI.

2. Simultaneous presence of gadolinium-enhancing and non-enhancing lesions at any time.

In primary progressive multiple sclerosis:

- Identical criteria for dissemination in space should be used for primary progressive multiple sclerosis and relapse-onset multiple sclerosis.

- CSF results should be considered for clinically uncertain cases of primary progressive multiple sclerosis. 
These criteria also recommend that at the time of diagnosis, a provisional disease course (relapsing-remiting, primary or secondary progressive MS) and if it the course is active or progressive (based on the previous year's history) should be specified and periodically re-evaluated based on the accumulated information. ${ }^{22}$

We recommend that the 2017 revised McDonald criteria $^{22}$ should be used for the diagnosis of MS when applicable.

Until now, in spite of the importance of MRI in MS diagnosis, McDonald criteria and subsequent revisions don't suggest how MRI sequences must be acquired, nor is it established in the Portuguese guidelines of MS Care. ${ }^{23,24}$ Recently, and to obviate this issue MRI expert guidelines were published suggesting a specific multi-sequence brain and spinal cord protocol in MS diagnosis and monitoring, being the diagnosis protocol more extensive due to differential diagnosis purposes. ${ }^{12-14}$

We recommend that a national diagnosis standardized MRI protocol, adapted to the Portuguese MS reality and based on the best and most recent scientific evidence, should be implemented. We also suggest that the adopted MRI protocols should warrant that MRI scans must be technically adequate, standardized and well positioned

Table 3 - MS diagnosis criteria (adapted from ref. 21)

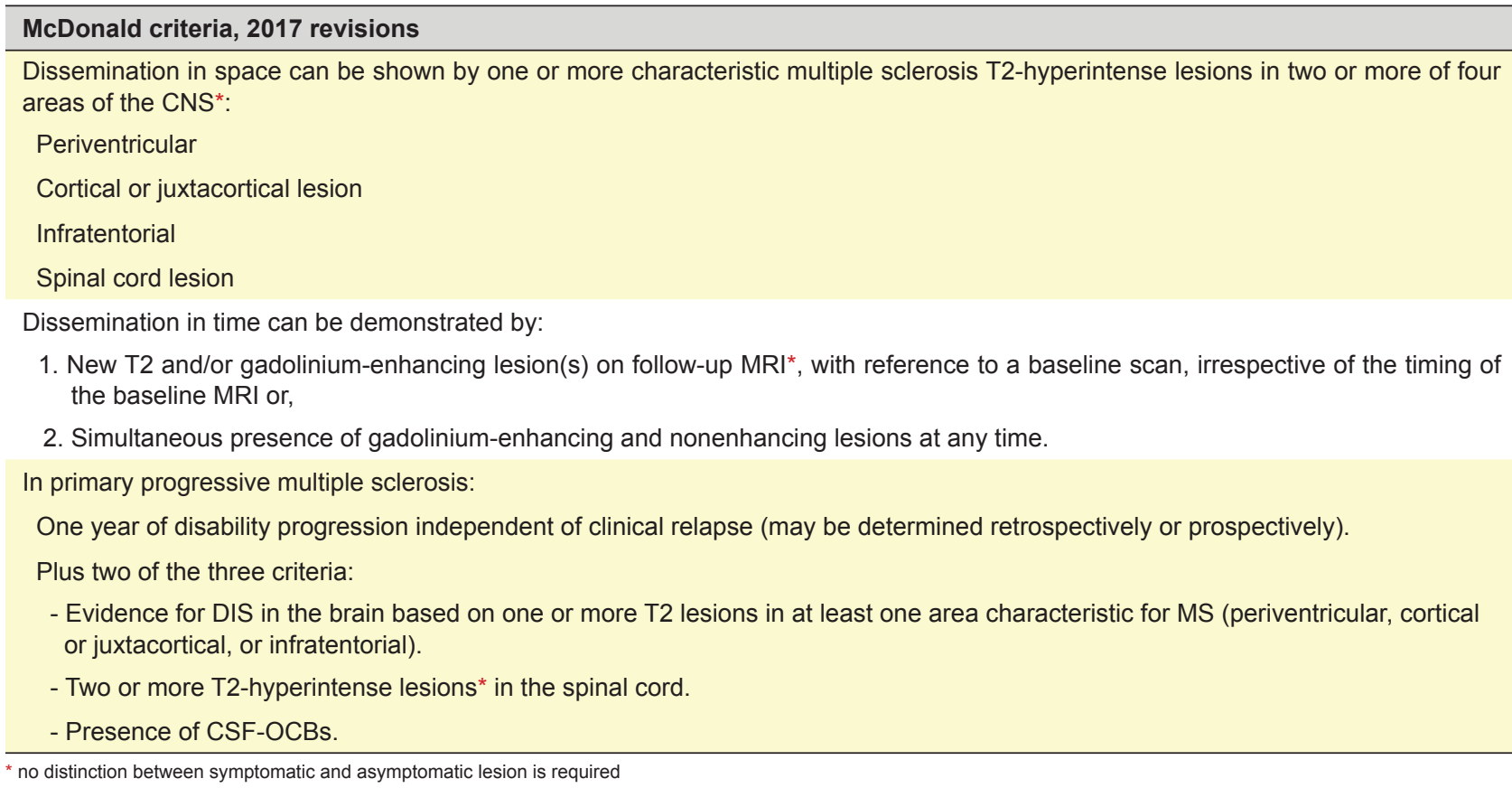

Table 4 - Referring physicians' clinical information (adapted from ref. 9, 13, 16, 18)

\begin{tabular}{l} 
Recommendations summary - referring physicians' clinical information diagnostic MRI protocol should include: \\
\hline Date of symptom onset and evolution; \\
Description of main clinical signs (i.e. subacute onset of optic neuritis, transverse myelitis or brainstem syndrome); \\
Description of clinical information considered important to differential diagnosis (i.e. past history of uveitis or other autoimmune \\
diseases); \\
Special needs such as claustrophobia, movement disorders (i.e. paroxistic spams, dystonia) or severe disabled patient; \\
Information about potential allergies, presence of potential incompatible MRI scan material, renal impairment/function.
\end{tabular}

Recommendations summary - referring physicians' clinical information follow-up MRI protocol should include:

Purpose of follow-up scan (disease activity, treatment-monitoring or safety/adverse effects surveillance MRI protocol);

Description of diagnosis (RIS, CIS or MS);

Description of clinical information considered important to differential diagnosis or MRI interpretation such as unexpected clinical signs, clinical decline, potential adverse effects;

DMT description and duration of treatment;

In PML surveillance study, description of treatment duration, JCV serostatus and previous DMT/immunosuppression (high or low risk patients);

Date and, if considered relevant, clinical information of last MRI performed;

Special needs such as claustrophobia, movement disorders (i.e. paroxistic spams, dystonia) or severe disabled patient;

Information about potential allergies, presence of potential incompatible MRI scans material, renal impairment/function. 
to permit future comparative analysis, should include instructions to perform a structured, systematic and comprehensive radiological report oriented to the clinical needs and, finally, with recommendations for referring physicians to provide sufficient clinical information in order to permit proper interpretation of imaging findings (Table 4). ${ }^{12,21}$

\begin{tabular}{l}
\hline Recommendations summary \\
MRI and MS diagnosis \\
\hline
\end{tabular}

- The 2017 revised McDonald criteria should be used for the diagnosis of MS when applicable.

- A national diagnosis standardized MRI protocol, adapted to the Portuguese MS reality and based on the best and most recent scientific evidence, should be implemented.

- The adopted MRI protocol should warrant that MRI scans must be technically adequate, standardized and well positioned.

- The adopted MRI protocols should include instructions on how to perform a structured, systematic and comprehensive radiological report oriented towards clinical needs.

- Referring physicians should provide sufficient clinical information in order to allow proper interpretation of imaging findings.

\section{a) MRI and MS diagnosis in a demyelinating first episode or clinical isolated syndrome}

Patients with $\mathrm{CIS}$ are those with a first clinical presentation of a disease that shows characteristics of inflammatory demyelination that could be MS but do not fulfill criteria of dissemination in time..$^{10}$ As shown in epidemiological and clinical trials, patients with $\mathrm{CIS}$ are at high risk of developing MS. ${ }^{10,25}$

The 2017 McDonald criteria now assist a clinician in making a MS diagnosis in a patient with a typical clinical CIS (i.e. subacute onset of optic neuritis, transverse myelitis or brainstem syndrome) in which the clinical and MRI criteria for DIS are met, CSF-OCBs are present and no better explanation for the clinical presentation is found. ${ }^{22}$

In patients with initial clinical symptoms suggestive of demyelinating disease or CIS, a good quality whole contrast enhanced (gadolinium) brain MRI respecting a standardized multi-sequence protocol with a minimum required sequences to aid in the diagnosis is recommended. . $9,112-17^{-17}$

When available, double inversion recovery sequences should also be performed in order to detect cortical or juxtacortical lesions, since they are now part of the 2017 McDonald DIS criteria. ${ }^{6,16,22}$ Additional MRI sequences can be added depending on the individual needs, clinical cases or differential diagnosis. ${ }^{9,13} \mathrm{MRI}$ brain scans should be at least $1.5 \mathrm{~T}$, since high field scanners have better sensibility in detecting demyelinating lesions. ${ }^{6}$

As in other countries, the access to MS experts/centers and MRI equipment in Portugal may vary in the different regions, and as a consequence patients may wait longer for a diagnosis. ${ }^{18}$ We agree with the recommendation stated in other expert MRI MS guidelines that in the presence of a possible demyelinating first episode, especially in patients with a typical CIS a diagnostic MRI should be performed as soon as possible, ideally, in a week since the initial symptoms.$^{18}$ As in other matters, the interpretation of this recommendation must be guided by clinical common sense since there are cases such as spinal cord compression suspicion or dubious, less typical MS symptoms, in which, this test must be, respectively, hastened or performed in the timing of other routine MRI exams. ${ }^{18}$

The demonstration of DIT, according to the 2017 McDonald criteria, in a CIS patient may now be achieved by the finding of a new T2 or gadolinium-enhanced lesion on a follow-up MRI brain scan at any time as compared to a reference scan; or the simultaneous presence of gadolinium-enhanced lesion and non-enhancing lesions at any time. ${ }^{22}$ In spite of the recent clarification of the McDonald 2010 DIS and DIT criteria by the 2017 revision (no distinction needs now to be made between symptomatic and asymptomatic MRI lesion to establish DIT and DIS) in some CIS patients it will be necessary to repeat MRI scans to demonstrate DIT. ${ }^{12,22}$ The best timing to perform a followup scan in CIS to look for evidence of DIT is debatable; nevertheless there are suggestions that a second MRI should be performed at an interval time of 3-6 months and a third one after 6 - 12 months if the later MRI still doesn't show DIT and then annually if the patient maintains this condition. ${ }^{5,12,13} \mathrm{~A}$ decrease in the frequency of MRI may be considered when CIS patients have been relapse free and radiologically stable during a follow-up of 3 to 5 years without DMT. MRI surveillance may be stopped if patients remain in this condition during a longer follow-up. ${ }^{13}$

Spinal cord MRI imaging is more difficult technically to perform due to the presence of artifacts and small tissue volume. ${ }^{23}$ Nevertheless spinal cord MRI adds diagnostic, prognostic and differential diagnosis value in $\mathrm{CIS}^{20,25-27}$ and should be included in the initial MRI workup. ${ }^{20,25,27}$ It is well known that spinal cord MRI is especially useful in the following situations: a) in CIS patients with few brain lesions, in which the demonstration of a clinical silent spinal lesion may help in the fulfillment of DIS thus reducing the need of a subsequent MRI appointment; b) in those CIS patients with atypical, equivocal or inconclusive MS presentations; c) and in the differential diagnosis of those patients with a first demyelinating episode suggesting spinal cord involvement.6,9,13,27 In order to reduce time and additional contrast administration this test should be performed in a "one stop shop" strategy and as with MRI brain scans, spinal MRI should be at least $1.5 \mathrm{~T}$, preferably 3.0T. ${ }^{12,23} \mathrm{CIS}$ patients should repeat spinal MRI in cases of unexpected worsening, spinal cord relapses or in suspicion of a secondary diagnosis. ${ }^{9,28}$ In CIS, it is not advisable to perform serial spinal MRI in order to show DIS and DIT and establish a MS diagnosis, since the spinal MRI role for this purpose is not fully established. ${ }^{12}$ 
Recommendations summary

MRI and MS diagnosis in a demyelinating first episode or clinical isolated syndrome.

- In CIS, the revised McDonald DIS and DIT 2017 criteria should be used for the diagnosis of MS when applicable.

- In CIS a $1.5 \mathrm{~T}$ preferably $3.0 \mathrm{~T}$, brain MRI respecting a standardized multisequence protocol with minimum required sequences to aid in the diagnosis should be performed.

- When available, double inversion recovery sequences should be performed in order to detect cortical or juxtacortical lesions.

- In the presence of a possible demyelinating first episode, a diagnostic MRI should be performed as soon as possible, ideally, in a week since initial symptoms.

- In CIS to look for evidence of DIT a second MRI should be performed at an interval time of 3 - 6 months and a third one after 6 - 12 months if the later MRI still doesn't show DIT and then annually if the patient maintains this condition.

- A decrease in the frequency of MRI may be considered when CIS patients have been relapse-free and radiologically stable during a follow-up of 3 to 5 years without DMT, MRI surveillance may be stopped if patients remain in this condition during a longer follow-up.

- Spinal cord MRI should be included in the CIS initial MRI workup and should be performed in a "one stop shop" strategy.

- It's not advisable to perform serial spinal MRI in CIS, in order to show DIS and DIT, nevertheless patients should repeat this exam in cases of unexpected worsening, spinal cord relapses or in suspicion of a secondary diagnosis.

b) MRI and MS diagnosis in relapsing-remitting and primary progressive multiple sclerosis

The revised 2017 McDonald criteria underpin the diagnosis of relapsing-remitting MS (RRMS) solely based on clinical DIT and DIS criteria. ${ }^{22}$ In spite of this evidence we recommend that even these patients should perform a brain MRI to confirm MS diagnosis and for differential diagnosis purposes. ${ }^{15,22}$

The primary-progressive MS (PPMS) diagnosis should be made based on the 2017 McDonald criteria. ${ }^{22}$ PPMS clinically diagnosed patients should perform a brain and spinal MRI to confirm MS diagnosis and to exclude diseases that may cause progressive disability. ${ }^{15,22}$

\section{Recommendations summary}

MRI and MS diagnosis in relapsing-remitting and primary progressive multiple sclerosis.

- A brain MRI to confirm MS and differential diagnosis purposes should be performed in patients in which the diagnosis RRMS may be solely based on clinical DIT and DIS criteria.

- PPMS patients should perform a brain and spinal MRI to confirm MS diagnosis, based on 2017 McDonald criteria, and for differential diagnosis purposes.

\section{c) MRI and MS diagnosis in radiologically isolated syndrome}

The relatively easy access to brain MRI to study other conditions (for instance headaches) has allowed clinicians to come in contact with patients that present a radiologically isolated syndrome (RIS), which is defined by the presence of brain lesions suggestive of inflammatory demyelination in the absence of clinical manifestations. ${ }^{10,12}$ Some of these MRI findings are unspecific but others are suggestive of a demyelinating pathology that carries a great risk of conversion to CIS or MS as defined by Okuda et al..$^{29}$ Since RIS criteria were published, several clinical and radiological predictors, which increase the risk of clinical progression, were identified, such as the presence of asymptomatic spinal cord lesions, a higher number of T2 lesions, younger age, pathological visual evoked potentials and presence of CSF-OCBs. ${ }^{29-32}$ The MRI criteria used to establish DIT and DIS in MS should be applied to assess RIS as proposed by the MAGNIMS group. ${ }^{6}$ In this particular group of patients it seems important for the clinical prognosis to perform, in the initial workup, spinal cord imaging. ${ }^{13,33}$ In RIS management there are three basic approaches: 'wait, follow or treat'. ${ }^{33}$ The 'wait' strategy proposes that no further follow-up is required and the patient is instructed to come back if symptoms occur. ${ }^{33}$ The 'follow' strategy is considered especially important in those patients who have the aforementioned risk factors. ${ }^{30,33}$ This strategy recommends clinical and radiological surveillance of patients at high risk, with the first radiological control suggested six months after the first MRI scan and a second scan after 24 months $^{33,34}$; other authors state that the time interval applied to the brain MRI follow-up of CIS patients should be enforced in these patients. ${ }^{12}$

Until now there are no consensus on the best timing, in RIS patients, to perform other diagnostic tests such as CSF study. ${ }^{30,33} \mathrm{MS}$ diagnosis in RIS, even in those with MRI DIS, DIT and with OCBs in CSF, should only be made in the presence of clinical symptoms. ${ }^{6}$ Since there is no consensus we suggest that RIS patients should be approached in an individually case-based manner and that the best timing to perform follow-up brain scans should be discussed with patient and the neuroradiological team. The 'treat' option in RIS is also not unanimous since the results of DMT treatment in RIS patients have been unclear and these kinds of treatments are not approved for these patients in most countries. ${ }^{30}$

\section{Recommendations summary}

MRI and MS diagnosis in radiologic isolated syndrome.

- RIS patients should be approached on an individual basis. Nevertheless, it is acceptable, in high at risk patients, that the first radiological control should be done six months after the first brain MRI scan and a second MRI scan should be performed 24 months later if the later MRI still does not show DIT.

- In patients with DIT we recommend that CSF study should be done, and if CSF-OCBs are found, we consider that the option to treat should be discussed with the patient.

- In patients in which the wait strategy is selected or if the decision to treat is based upon the presence of clinical symptoms we recommend that only clinical surveillance should be made thus obviating the need of performing brain MRI follow-up.

- Spinal cord MRI should be included in the RIS initial MRI workup and should be performed in a 'one stop shop' strategy. 


\section{MRI and disease activity monitoring; therapy efficacy and adverse therapy effects}

\section{a) MRI and disease activity monitoring}

In RRMS patient's disease activity is detected much more frequently in brain MRI scans than with clinical assessment of relapses, being the reason why this test is extremely useful in monitoring the disease course and response to treatment. ${ }^{10,14,16}$ On the other hand spinal cord MRI is less sensitive than brain MRI to detect new demyelinating lesions, particularly contrast-enhancing lesions and it's thought to have a limited role in the routine MS follow-up. ${ }^{14}$

We recommend that a minimum national follow-up standardized MRI protocol, adapted to the Portuguese MS reality and based on the best and most recent scientific evidence, should be implemented. To better monitor MS disease activity, as a general rule, we recommend, if possible, that all follow-up brain MRI exams should be done in the same, at least 1.5T, MRI scanner with the same standardized image protocol. ${ }^{13-15}$ In follow-up MRI scans clinicians should give accurate and relevant information in the MRI request form, such as pertinent clinical history and current DMT (Table 4), and neuroradiologists should include standardized terminology and information, for instance demyelinating lesion numbers and specific location. ${ }^{9}$ Also, at follow-up scans, previous scans should be available to correctly compare MRI scans and patients are encouraged to keep copies of their own exams on portable digital media in order to have this available when the follow-up examination is performed in a different imaging center or receive care of other health professional outside their usual outpatient-clinic. ${ }^{9,13,18}$

Due to the interindividual variability of MS activity in patients and albeit the importance of follow-up brain MRI in RRMS patients, there is not a general rule that states what is the best time interval to perform follow up scans. ${ }^{13}$ Still, and to better establish individual disease activity; it is advisable that a follow-up brain MRI should be obtained 3-6 months after a first diagnostic MRI. ${ }^{13}$ Depending of disease activity a second MRI follow-up should be obtained 6 - 12 months after the first follow-up, and thereafter annually if disease activity remains stable. ${ }^{13}$ However it is recognized that a MRI should be repeated as soon as possible in unplanned situations such as unexpected cases of clinical deterioration, unexpected disease progression or breakthrough activity and in re-evaluation of MS diagnosis..,18 Similar to CIS, repetition of spinal cord MRI in RRMS should only be done when atypical spinal symptoms occur or in the suspicion of another spinal cord disease. ${ }^{14,16}$
Recommendations summary

\section{MRI and disease activity monitoring}

- A minimum national MS follow-up standardized MRI protocol adapted to the Portuguese MS reality should be implemented.

- All follow-up brain MRI exams should be done in the same, at least $1.5 \mathrm{~T}, \mathrm{MRI}$ scanner with the same standardized image protocol.

- In follow-up MRI exams clinicians should give important and relevant information in the MRI request form and neuroradiologists must include standardized terminology and information in their reports.

- Previous examinations should be available to correctly compare MRI scan and patients are encouraged to keep copies of their own exams on portable digital media in order to have this available when the follow-up assessment is done.

- It's advisable that a follow-up brain MRI should be obtained 3 - 6 months after a first diagnostic MRI and depending of disease activity a second MRI follow-up should be obtained 6 - 12 months after the first follow-up, and thereafter annually if disease activity remains stable.

- Brain MRI should be repeated, as soon as possible, in unplanned situations, such as unexpected cases of clinical deterioration, unexpected disease progression or breakthrough activity and in re-evaluation of MS diagnosis.

- Repetition of spinal cord MRI in RRMS should only be done when atypical spinal symptoms occur or in the suspicion of another spinal cord disease.

\section{b) MRI and therapy efficacy monitoring}

In order to monitor therapy efficacy and to early identify therapy non-responders, that will allow a prompt switch to a more effective treatment, in patients initiating DMT a follow-up MRI scan with gadolinium enhancement should be planed at 6 and 12 months after therapy initiation, then yearly thereafter. ${ }^{14,16,18}$ The timing of the first therapy reference scan must take into account the time that some drugs may take to be fully efficacious. ${ }^{16}$ If DMT change is thought an MRI should be considered shortly before the therapy replacement. ${ }^{13}$

There is no agreement when to decrease the frequency of MRI examinations nonetheless it seems acceptable that fewer MRI imaging scans (e.g. every two or three years) should be done: in later stages of the disease (progressive MS forms) in which MRI imaging activity is low and no effective treatments are yet available, in clinical and radiological stable MS patients without a change in DMT and with favorable outcome disease factors and in clinical and radiological stable older MS patients (> 55 - 60 yearsold) without DMT and with favorable outcome disease factors. 9,13,18

Cerebral and spinal volume and other non-conventional advanced MRI techniques have shown promising results in MS clinical management and as markers of disease progression, however, they still have to be fully validated and standardized in order to be performed in clinical practice. ${ }^{14}$ 
Recommendations summary

MRI and therapy efficacy monitoring

- In patients initiating DMT a follow-up MRI scan with gadolinium enhancement should be planned at 6 and 12 months after therapy initiation, then yearly thereafter

- If a DMT change is thought, an MRI should be considered shortly before the therapy replacement; the decrease of the frequency of MRI examinations in DMT treated patients may seem admissible in some cases.

- Except in clinical and neuroradiological investigational purposes we do not recommend performing nonconventional advanced MRI techniques in the clinical practice.

\section{c) MRI and adverse effects monitoring}

The importance of MRI in the surveillance of potential therapy adverse effects was put on notice in the case of natalizumab-associated progressive multifocal leukoencephalopathy (PML), a potential life-threatening condition due to reactivation of the John Cunningham virus (JCV). ${ }^{14}$ $\mathrm{MRI}$ is known to aid in the early detection of natalizumabassociated PML brains lesions. It can detect these lesions on asymptomatic or presymptomatic PML stages, thus improving the patient's survival and functional outcome. ${ }^{14}$ Natalizumab treated patients should follow a surveillance MRI protocol based on JCV seropositive status, length of drug exposure time and previous use of immunosuppressive drugs. 9,13,14 Higher risk PML patients (seropositive for JCV with > 18 months of natalizumab exposure) should perform a PML brain imaging protocol every $3-6$ months. ${ }^{9}$ If there is any clinical change suspicious of this condition MRI should be anticipated. 9,14 In low risk PML patients (seronegative JCV patients), PML brain imaging protocol should be done annually. ${ }^{14}$ The surveillance PML MRI protocol, must include T2-Flair and diffusion-weighted sequences in combination with conventional T2-weighed images. ${ }^{14}$ In cases of JCV seropositive patients that are going to switch from natalizumab to another DMT a baseline MRI should be done one month prior to switching therapy and then a follow-up MRI should be repeated three months after natalizumab cessation. ${ }^{13,18} \mathrm{MRI}$ is also important in the in follow-up of PML, since it allows the early detection of the PML-immune reconstitution syndrome. ${ }^{14}$ The role of MRI in pharmacovigilance is not reduced to $\mathrm{PML}$, since this test can be useful in the diagnosis of other treatment complications for instance in the detection of other opportunistic infections leading to encephalitis/meningitis (such as Varicella zoster or Listeria) and the detection of paradoxical reactions such as rebound inflammatory activity or overwhelming inflammatory demyelination that can occur with some DMTs. ${ }^{14}$

\section{Recommendations summary}

\section{MRI and adverse therapy effects monitoring}

- Natalizumab treated patients should follow a surveillance MRI protocol based on JCV seropositive status, length of drug exposure time and previous use of immunosuppressive drugs.

- Higher risk PML patients should perform a PML brain imaging protocol every $3-6$ months, or sooner in case of any suspicious clinical changes.

- In low risk PML (seronegative) patients a brain imaging protocol should be done annually.

- In JCV seropositive patients that are going to switch from natalizumab to another DMT a baseline MRI should be done one month prior to switching therapy and then a follow-up MRI should be repeated three months after natalizumab cessation.

\section{CONCLUSION}

$M R I$ is established as a recognizable tool in the diagnosis and monitoring of MS patients. In these first Portuguese MRI consensus recommendations we provide some practical guidelines to promote standardized strategies to be applied in the clinical practice setting of Portuguese healthcare professionals. Our recommendations are based on the available clinical evidence and best practices; however, due to the rapidly changing knowledge in the MS field these guidelines should be periodically updated. Finally, we hope that these MRI guidelines will serve to optimize MS management and improve MS patient care throughout Portugal.

\section{OBSERVATIONS}

Sociedade Portuguesa de Neurorradiologia - Forum de Estudo da Esclerose Múltipla is composed by Neuroradiologists Ana Filipa Geraldo, Ana Mafalda Reis, Daniela Seixas, Inês Carreiro, Isabel Cravo, Joana Barreira, Joana Graça, José Manuel Amorim, Luís Augusto, Marta Maia Safronova, Olga Brito, Pedro de Melo Freitas, Pedro Vilela, Rosa Cruz, Sérgio Galo, Solange Lopes da Silva and Teresa Palma.

\section{PROTECTION OF HUMANS AND ANIMALS}

The authors declare that the procedures were followed according to the regulations established by the Clinical Research and Ethics Committee and to the Helsinki Declaration of the World Medical Association.

\section{DATA CONFIDENTIALITY}

The authors declare having followed the protocols in use at their working center regarding patients' data publication.

\section{CONFLICTS OF INTEREST}

All authors report no conflict of interest.

\section{FUNDING SOURCES}

This work had a investigational grant from Roche Farmacêutica Química LDA: EPAM129844-G. 


\section{REFERENCES}

1. Compston A, Coles A. Multiple sclerosis. Lancet. 2008;372:1502-17.

2. de Sa J, Alcalde-Cabero E, Almazan-Isla J, Garcia-Lopez F, de PedroCuesta J. Incidence of multiple sclerosis in Northern Lisbon, Portugal: 1998-2007. BMC Neurol. 2014;14:249.

3. McDonald WI, Compston A, Edan G, Goodkin D, Hartung HP, Lublin FD, et al. Recommended diagnostic criteria for multiple sclerosis: guidelines from the International Panel on the diagnosis of multiple sclerosis. Ann Neurol. 2001;50:121-7.

4. Polman $\mathrm{CH}$, Reingold SC, Banwell B, Clanet M, Cohen JA, Filippi M, et al. Diagnostic criteria for multiple sclerosis: 2010 revisions to the McDonald criteria. Ann Neurol. 2011;69:292-302.

5. Polman $\mathrm{CH}$, Reingold SC, Edan G, Filippi M, Hartung HP, Kappos L, et al. Diagnostic criteria for multiple sclerosis: 2005 revisions to the "McDonald Criteria". Ann Neurol. 2005;58:840-6.

6. Filippi M, Rocca MA, Ciccarelli O, De Stefano N, Evangelou N, Kappos $\mathrm{L}$, et al. MRI criteria for the diagnosis of multiple sclerosis: MAGNIMS consensus guidelines. Lancet Neurol. 2016;15:292-303.

7. van Munster CE, Uitdehaag BM. Outcome measures in clinical trials for multiple sclerosis. CNS Drugs. 2017;31:217-36.

8. Lovblad KO, Anzalone N, Dorfler A, Essig M, Hurwitz B, Kappos L, et al. MR imaging in multiple sclerosis: review and recommendations for current practice. AJNR Am J Neuroradiol. 2010;31:983-9.

9. Traboulsee A, Simon JH, Stone L, Fisher E, Jones DE, Malhotra A, et al. Revised recommendations of the Consortium of MS Centers Task Force for a Standardized MRI Protocol and clinical guidelines for the diagnosis and follow-up of multiple sclerosis. AJNR Am J Neuroradiol. 2016;37:394-401.

10. Lublin FD, Reingold SC, Cohen JA, Cutter GR, Sorensen PS, Thompson AJ, et al. Defining the clinical course of multiple sclerosis: the 2013 revisions. Neurology. 2014;83:278-86.

11. Curley M, Josey L, Lucas R, Dear K, Taylor BV, Coulthard A, et al. Adherence to MRI protocol consensus guidelines in multiple sclerosis: an Australian multi-centre study. J Med Imaging Radiat Oncol. 2012;56:594-8.

12. Rovira A, Wattjes MP, Tintore M, Tur C, Yousry TA, Sormani MP, et al. Evidence-based guidelines: MAGNIMS consensus guidelines on the use of MRI in multiple sclerosis-clinical implementation in the diagnostic process. Nat Rev Neurol. 2015;11:471-82.

13. Vagberg M, Axelsson M, Birgander R, Burman J, Cananau C, Forslin $Y$, et al. Guidelines for the use of magnetic resonance imaging in diagnosing and monitoring the treatment of multiple sclerosis: recommendations of the Swedish Multiple Sclerosis Association and the Swedish Neuroradiological Society. Acta Neurol Scand. 2017;135:1724.

14. Wattjes MP, Rovira A, Miller D, Yousry TA, Sormani MP, de Stefano MP, et al. Evidence-based guidelines: MAGNIMS consensus guidelines on the use of MRI in multiple sclerosis-establishing disease prognosis and monitoring patients. Nat Rev Neurol. 2015;11:597-606.

15. Rovira A, Tintoré M, Alvarez-Cermeño J, Izquierdo G, Prieto J. Recommendations for using and interpreting magnetic resonance imaging in multiple sclerosis. Neurología. 2010;25:248-65.

16. Filippi M, Rocca MA, Bastianello S, Comi G, Gallo P, Gallucci M, et al. Guidelines from The Italian Neurological and Neuroradiological Societies for the use of magnetic resonance imaging in daily life clinical practice of multiple sclerosis patients. Neurol Sci. 2013;34:2085-93.

17. Cotton F, Kremer S, Hannoun S, Vukusic S, Dousset V, Imaging Working
Group of the Observatoire Francais de la Sclerose en P. OFSEP, a nationwide cohort of people with multiple sclerosis: Consensus minimal MRI protocol. J Neuroradiol. 2015;42:133-40.

18. Traboulsee A, Letourneau-Guillon L, Freedman MS, O'Connor PW, Bharatha A, Chakraborty S, et al. Canadian Expert Pane recommendations for MRI use in MS diagnosis and monitoring. Can $\mathrm{J}$ Neurol Sci. 2015;42:159-67.

19. Verhey LH, Narayanan S, Banwell B. Standardized magnetic resonance imaging acquisition and reporting in pediatric multiple sclerosis. Neuroimaging Clin N Am. 2013;23:217-26 e211-7.

20. Simon JH. The contribution of spinal cord MRI to the diagnosis and differential diagnosis of multiple sclerosis. J Neurol Sci. 2000;172:S325.

21. Rovira A, Leon $A$. MR in the diagnosis and monitoring of multiple sclerosis: an overview. Eur J Radiol. 2008;67:409-14.

22. Thompson AJ, Banwell BL, Barkhof F, Carroll WM, Coetzee T, Comi G, et al. Diagnosis of multiple sclerosis: 2017 revisions of the McDonald criteria. Lancet Neurol. 2018;17:162-73.

23. Wattjes MP, Steenwijk MD, Stangel M. MRI in the diagnosis and monitoring of multiple sclerosis: an update. Clin Neuroradiol. 2015;25:S157-65.

24. Direção Geral da Saúde. Organização de Cuidados na Esclerose Múltipla. 2012. [accessed 2018 Jan 14]. Available from: http://nocs.pt/ wp-content/uploads/2017/10/organizacao-de-cuidados-na-esclerosemultipla.pdf.

25. Odenthal $C$, Coulthard $A$. The prognostic utility of MRI in clinically isolated syndrome: a literature review. AJNR Am J Neuroradiol. 2015;36:425-31.

26. Peixoto $S$, Abreu P. Alterações na ressonância magnética preditoras da conversão da síndrome clinicamente isolada em esclerose múltipla. Acta Med Port. 2016;29:742-8.

27. Kearney $\mathrm{H}$, Miller DH, Ciccarelli O. Spinal cord MRI in multiple sclerosis-diagnostic, prognostic and clinical value. Nat Rev Neurol. 2015;11:32738.

28. Oreja-Guevara C, Paradig MS. Overview of magnetic resonance imaging for management of relapsing-remitting multiple sclerosis in everyday practice. Eur J Neurol. 2015;22:S22-7.

29. Okuda DT, Mowry EM, Beheshtian A, Waubant E, Baranzini SE, Goodin DS, et al. Incidental MRI anomalies suggestive of multiple sclerosis: the radiologically isolated syndrome. Neurology. 2009;72:800-5.

30. Niino N, Miyazaki Y. Radiologically isolated syndrome and clinically isolated syndrome. Clin Exp Neuroimmunol. 2017;8:S24-32.

31. Okuda DT, Siva A, Kantarci O, Inglese M, Katz I, Tutuncu M, et al. Radiologically isolated syndrome: 5-year risk for an initial clinical event. PLoS One. 2014;9:e90509.

32. Lebrun C. The radiologically isolated syndrome. Rev Neurol. 2015;171:698-706

33. Granberg T, Martola J, Kristoffersen-Wiberg M, Aspelin P, Fredrikson S. Radiologically isolated syndrome-incidental magnetic resonance imaging findings suggestive of multiple sclerosis, a systematic review. Mult Scler. 2013;19:271-80.

34. Lebrun C, Bensa C, Debouverie M, Wiertlevski S, Brassat D, de Seze $\mathrm{J}$, et al. Association between clinical conversion to multiple sclerosis in radiologically isolated syndrome and magnetic resonance imaging, cerebrospinal fluid, and visual evoked potential: follow-up of 70 patients. Arch Neurol. 2009;66:841-6. 